\title{
Adsorption Efficiency of Sawdust in Activated and Surface-Modified Forms - A Comparative Study
}

\author{
K.M. TAJUN MEERA BEGUM ${ }^{\mathrm{a}}$ and N.M.I. ALHAJI ${ }^{* b}$ \\ ${ }^{a}$ Department of Chemistry, Avvaiyar Government College for Women, \\ Karaikal-609602, Pondicherry, India \\ ${ }^{b}$ P.G. and Research Department of Chemistry, Khadir Mohideen College, \\ Adirampattinam- 614701, India \\ alhajinmi@hotmail.com
}

Received 24 July 2013 / Accepted 8 August 2013

\begin{abstract}
Two different forms of sawdust, viz., acid-activated sawdust in powder form (ASDP) and surface-modified sawdust in bead form (SDCCB) were prepared and used as adsorbents for the removal of chromium(VI) from aqueous solution. Batch experiments were carried out to investigate the potential efficiency of the two forms of sawdust to remove $\mathrm{Cr}(\mathrm{VI})$ ions from aqueous solution as a function of the initial $\mathrm{Cr}(\mathrm{VI})$ concentration, $\mathrm{pH}$, contact time, agitation speed and temperature. Based on Langmuir isotherms, the maximum adsorption capacity was found to be $45.5 \mathrm{mg} / \mathrm{g}$ for ASDP and $125 \mathrm{mg} / \mathrm{g}$ for SDCCB. Equilibrium was found to be attained at about $120 \mathrm{~min}$ and 150 min respectively for ASDP and SDCCB. Various isotherms and kinetic models were fitted to describe the solid-solute interaction and the activation parameters were evaluated in both the cases. Based on the results, it has been suggested that the sorption of $\mathrm{Cr}(\mathrm{VI})$ on surface of both sawdust adsorbents is an endothermic, a spontaneous and a nonspecific-chemisorption process.
\end{abstract}

Keywords: Sawdust, Adsorption capacity, Adsorption isotherms, Kinetics, Thermodynamic parameters

\section{Introduction}

Despite the availability of numerous techniques for the treatment of effluents with heavy toxic metals, adsorption is constantly viewed as the highly effective technique. Agricultural by-products are mostly composed of lignin and cellulose as well as other polar poly functional groups like alcohols, aldehydes, ketones, carboxylate, phenols and ethers. These groups are able to bind heavy metals through replacement of hydrogen ions with metal ions in solution or by donation of an electron pair to form complexes with the metal ion in solution ${ }^{1,2}$. Therefore, biomass like rice husk, seaweeds, sawdust, chitosan etc. have been recognised as effective, eco-friendly low-cost adsorbents because of their remarkable properties such as hydrophilic character, sufficient flexibility of linear chain, cationic properties of polysaccharides, presence of polar poly functional groups, bio degradability and bio comparability. But in recent years, surface modification is being done chemically, physically or biologically to enhance their ion-exchange properties through the creation of surface functionality ${ }^{3,4}$. 
Hexavalent chromium is one of the harmful heavy metals because of its carcinogenetic nature and also wide application in industries such as electroplating, leather tanning, mining, dyes and pigments, steel fabrication, canning industries etc. Due to its severe toxicity, Environmental Protection Agency, Cincinaati, USA set the tolerance limit for the discharge of $\mathrm{Cr}(\mathrm{VI})$ ions into surface water as $0.1 \mathrm{mg} / \mathrm{L}$ and in potable water as $0.05 \mathrm{mg} / \mathrm{L}$. Thus the removal of $\mathrm{Cr}(\mathrm{VI})$ ions is mandatory.

Hence in the present study, sawdust (ligno cellulose polysaccharide) has been chosen as the precursor and its two surface-modified forms, activated sawdust powder (ASDP) and sawdustchitosan composite bead (SDCCB) have been employed in separate experiments for the adsorption of $\mathrm{Cr}(\mathrm{VI})$ ions from aqueous solution. Results from these studies have been compared to decide which of these two forms is better in removing $\mathrm{Cr}(\mathrm{VI})$ from toxic effluents.

\section{Experimental}

Saw dust was collected from the local saw mill. Potassium dichromate (AR) was used for the preparation of $\mathrm{Cr}(\mathrm{VI})$ stock solution. Chemicals such as sulphuric acid, hydrogen peroxide and nitric acid were purchased from Merck India. The $\mathrm{pH}$ of the solutions was maintained by hydrochloric acid - potassium chloride for the range of $\mathrm{pH} 1-3$, acetic acid - sodium acetate for the range of $\mathrm{pH} 4-6$ and boric acid - sodium hydroxide for the range of $\mathrm{pH}$ 8-10. Sigma Aldrich analytical grade reagents of 1,5-diphenyl carbazide and acetone were used for analyzing the chromium ions. Double distilled water was used for preparing all the solutions.

\section{Preparation of ASDP}

Sawdust was charred thoroughly by the careful addition of conc. $\mathrm{H}_{2} \mathrm{SO}_{4}$, washed with sodium carbonate and distilled water and dried in hot air oven at $100{ }^{\circ} \mathrm{C}$. The dried sample was treated with $\mathrm{H}_{2} \mathrm{O}_{2}(10 \mathrm{~mL})$ in a water bath at $50{ }^{\circ} \mathrm{C}$ for 30 minutes and then $10 \%$ conc. $\mathrm{HNO}_{3}$ was added with constant stirring at $70{ }^{\circ} \mathrm{C}$ for about 40 minutes. The sample was then washed and dried to get the activated sawdust powder.

\section{Preparation of SDCCB}

Saw dust was treated with sulphuric acid for $2 \mathrm{~h}$ Then it was neutralized with distilled water and dried in a hot air oven at $100{ }^{\circ} \mathrm{C}$. Chitosan gel was prepared by dissolving $3 \mathrm{~g}$ of chitosan in $100 \mathrm{~mL}$ of $2 \%$ acetic acid. $3 \mathrm{~g}$ of acid treated saw dust was added to the chitosan gel and kept in a rotary shaker for $12 \mathrm{~h}$ at $200 \mathrm{rpm}$. Then this solution was dropped into $0.5 \mathrm{~mol} / \mathrm{L} \mathrm{NaOH}$ solution which was kept for $12 \mathrm{~h}$. The composite beads thus obtained were washed with distilled water to remove excess $\mathrm{NaOH}$. Cross linking was done by immersing the beads in ethanolic $7.5 \%$ glutaraldehyde solution for $24 \mathrm{~h}$. The beads were then washed and dried to get the sawdust chitosan composite beads.

Both ASDP and SDCCB were characterized by using BET analyzer (Micromeritics), and FTIR spectrophotometer (Perkin Elmer, spectrum RXI) to identify the presence of activation in the adsorbents.

\section{Method}

Batch adsorption studies were conducted by shaking $25 \mathrm{~mL}$ of desired quantity of aqueous $\mathrm{Cr}(\mathrm{VI})$ solution with $0.1 \mathrm{~g}$ adsorbent and $\mathrm{pH} 2.0$ at $200 \mathrm{rpm}$ speed to determine the equilibrium time. The supernatant liquid samples were filtered periodically and then analyzed by using Jasco UV spectrophotometer at $540 \mathrm{~nm}$ to calculate the adsorption capacity and percentage removal efficiency. The amount of adsorption, $q_{t}(\mathrm{mg} / \mathrm{g})$ and percentage removal were calculated using Eqs. (1) and (2). 


$$
\begin{aligned}
q_{t} & =\left(C_{o}-C_{t}\right) \mathrm{V} / \mathrm{m} \\
\text { Percentage removal } & =\left[\left(C_{o}-C_{F}\right) / C_{o}\right] \times 100
\end{aligned}
$$

Where $C_{o}$ and $C_{t}$ are the initial concentration and concentration at any instant $(\mathrm{mg} / \mathrm{L}), \mathrm{V}$ is the volume of solution (l), $q_{t}$ is the adsorption capacity $(\mathrm{mg} / \mathrm{g}$ ) at time $\mathrm{t}, m$ is the weight of adsorbent $(\mathrm{g})$ and $C_{F}$ is the solution concentration at the end of the adsorption process $(\mathrm{mg} / \mathrm{L})$.

\section{Results and Discussion}

Adsorption usually depends on the surface area available on the adsorbent. The BET analysis shows the specific surface area of ASDP and SDCCB to be $321 \mathrm{~m}^{2} / \mathrm{g}$ and $30 \mathrm{~m}^{2} / \mathrm{g}$ respectively.

FTIR results confirm the presence of polar poly functional groups in ASDP and SDCCB (Figures 1 and 2). The significant changes of functional groups are visible due to the different mode of activation carried out in the two adsorbents. The successive acid treatment in the case of ASDP hydrolyzes the amides and esters of ligno cellulosic polymer into acid, alcohol and amines which are confirmed by their corresponding absorbance peaks in FTIR spectrum (Figure 1).

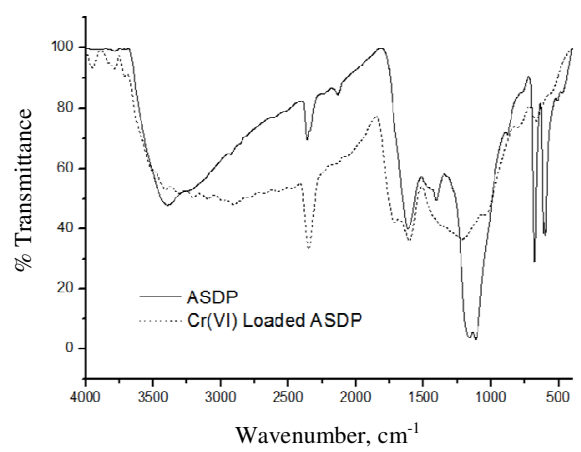

Figure 1. FTIR spectra of raw and $\mathrm{Cr}$ loaded ASDP

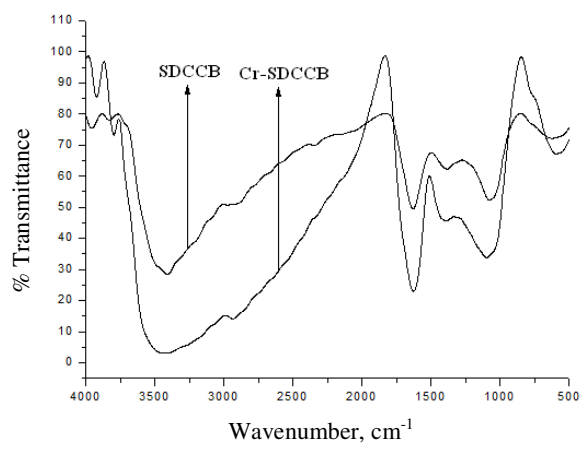

Figure 2. FTIR spectra of raw and $\mathrm{Cr}$ loaded SDCCB

Table 1 lists the functional groups and shift in the functional group of dominant peaks of SDCCB on $\mathrm{Cr}(\mathrm{VI})$ adsorption. These shifts in the wave number indicate the adsorption of $\mathrm{Cr}(\mathrm{VI})$ ion on the surface of the SDCCB.

Table 1. Functional groups present in SDCCB and Cr-loaded SDCCB

\begin{tabular}{lcc}
\hline \multirow{2}{*}{ Functional groups } & \multicolumn{2}{c}{ Functional group frequencies, $\mathrm{cm}^{-1}$} \\
\cline { 2 - 3 } & SDCCB & Cr-loaded SDCCB \\
\hline O-H (H bonded) and NH stretching & 3408.36 & 3412.3 \\
N-H bending vibrations & 1631.10 & 1627.48 \\
C-O and O-H bending & 1383.62 & 1385 \\
C-N stretching & 1075.08 & 1097 \\
$\mathrm{NH}_{2}$ and NH wagging & 622.70 & 594.5 \\
\hline
\end{tabular}

The studies of effect of contact time, agitation speed and $\mathrm{pH}$ on the adsorption capacity of $\mathrm{Cr}(\mathrm{VI})$ ions reveal that equilibrium is reached at nearly $120 \mathrm{~min}$ in the case of ASDP and $150 \mathrm{~min}$ in the case of SDCCB and maximum adsorption occurs at $200 \mathrm{rpm}$ and pH 2.0 with respect to both the adsorbents. 
The amount of chromium adsorbed for different initial concentration onto ASDP and SDCCB is shown in Figure 3. For ASDP (Figure 3a), the adsorption capacity increases from $6.1 \mathrm{mg} / \mathrm{g}$ to $42.4 \mathrm{mg} / \mathrm{g}$ and percentage removal decreases from $98 \%$ to $68 \%$ in the initial concentrations ranging from $25 \mathrm{ppm}$ to $250 \mathrm{ppm}$. For SDCCB (Figure 3b), the adsorption capacity increases from $11.1 \mathrm{mg} / \mathrm{g}$ to $101.1 \mathrm{mg} / \mathrm{g}$ and $\%$ removal decreases from $95 \%$ to $80.9 \%$ in the initial concentrations ranging from $100 \mathrm{ppm}$ to $500 \mathrm{ppm}$.
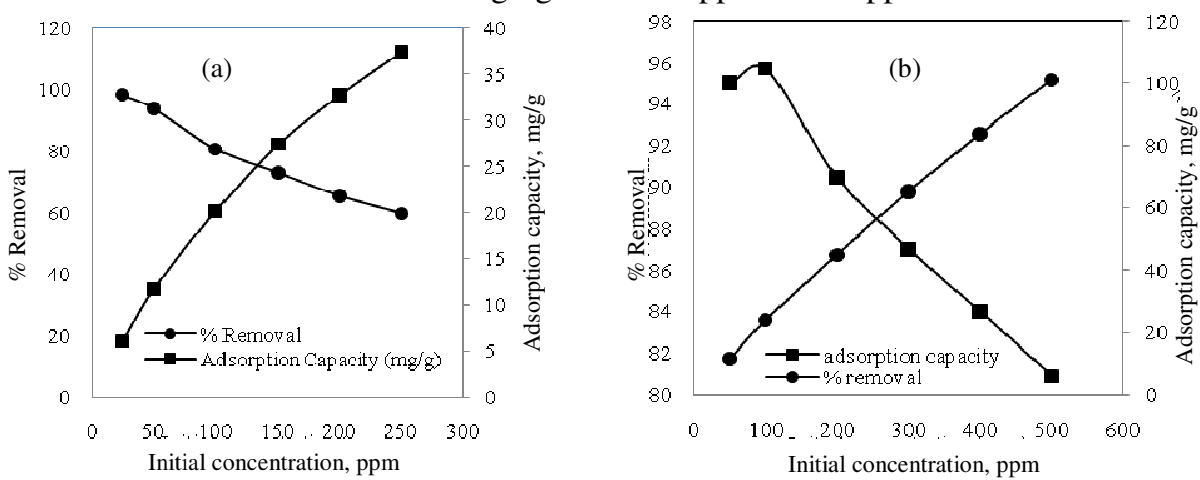

Figure 3. Effect of initial concentration on adsorption of $\mathrm{Cr}(\mathrm{VI})$ ions on (a) ASDP and (b) $\operatorname{SDCCB}(\mathrm{m}=0.1 \mathrm{~g}, \mathrm{pH}=2, \mathrm{~V}=25 \mathrm{~mL}$, Speed $=200 \mathrm{rpm})$

In adsorption process, the initial $\mathrm{Cr}(\mathrm{VI})$ concentration acts as a driving force to overcome the mass transfer between the adsorbent and $\mathrm{Cr}(\mathrm{VI})$ ions. In general, at lower concentrations of $\mathrm{Cr}(\mathrm{VI})$ there are sufficient active sites to occupy. However in higher concentration of $\mathrm{Cr}(\mathrm{VI})$, they are left unadsorbed due to the saturation of binding sites of the adsorbent ${ }^{5,6}$. For the initial $\mathrm{Cr}(\mathrm{VI})$ concentration value of $180 \mathrm{ppm}$, the optimum values (the point of intersection in the Figure 3 ) of percentage removal and adsorption capacity are found to be $77 \%$ and $33.5 \mathrm{mg} / \mathrm{g}$ respectively for $\operatorname{ASDP}\left(\mathrm{C}_{\mathrm{o}}=180 \mathrm{ppm}\right)$ and $87.85 \&$ $65.3 \mathrm{mg} / \mathrm{g}$ respectively for SDCCB $\left(\mathrm{C}_{\mathrm{o}}=300 \mathrm{ppm}\right)$.

The effect of temperature on adsorption of $\mathrm{Cr}(\mathrm{VI})$ ions was investigated for $\operatorname{ASDP}\left(\mathrm{C}_{\mathrm{o}}=\right.$ $100 \mathrm{ppm})$ and SDCCB $\left(\mathrm{C}_{\mathrm{o}}=200 \mathrm{ppm}\right)$ by varying the temperature from $30^{\circ} \mathrm{C}$ to $70{ }^{\circ} \mathrm{C}$ (Figure 4). The maximum adsorption capacity was observed at $70{ }^{\circ} \mathrm{C}$. The increase in adsorption capacity with increase in temperature may be due to the formation of some new adsorption sites on the surface of the adsorbent, the enlargement of the pores and also the increased rate of intra-particle diffusion of $\mathrm{Cr}(\mathrm{VI})$ ions into the pores of adsorbent.

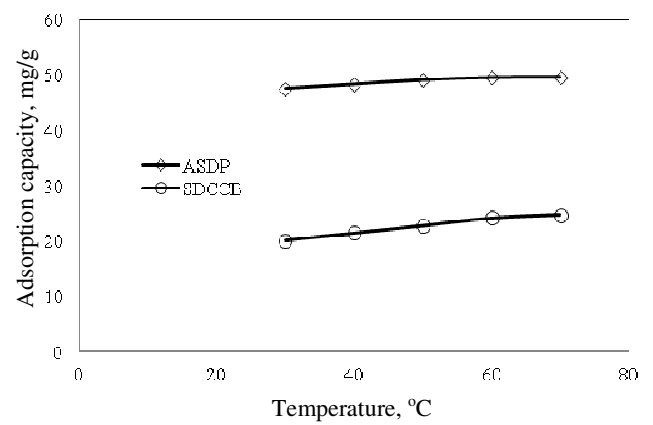

Figure 4. Effect of temperature on adsorption of $\mathrm{Cr}(\mathrm{VI})$ on ASDP and SDCCB $(\mathrm{m}=0.1 \mathrm{~g}$, $\mathrm{pH}=2, \mathrm{~V}=25 \mathrm{~mL}$, Speed $=200 \mathrm{rpm}$ ) 
Various isotherm equations like Langmuir, Freundlich and Temkin were used to describe $^{7}$ the equilibrium characteristics of adsorption of chromium by SDCCB and ASDP. The linearised form of isotherms and the constants obtained from the slope and intercept are listed in Table 2.

Table 2. Summary of parameters for various isotherm models

\begin{tabular}{|c|c|c|c|}
\hline Isotherm Model & Equation & $\begin{array}{l}\text { Constants for } \\
\text { SDCCB }\end{array}$ & $\begin{array}{c}\text { Constants for } \\
\text { ASDP }\end{array}$ \\
\hline Langmuir & $\begin{array}{c}\frac{C_{e}}{q_{e}}=\frac{1}{b \theta}+\frac{C_{e}}{\theta} \\
K_{L}=\theta \cdot b \\
R_{L}=\frac{1}{1+b C_{o}}\end{array}$ & $\begin{array}{l}\theta=125 \mathrm{mg} / \mathrm{g} \\
\mathrm{b}=0.04 \mathrm{~L} / \mathrm{mg} \\
\mathrm{K}_{\mathrm{L}}=5 \mathrm{~L} / \mathrm{g} \\
\mathrm{R}_{\mathrm{L}}=0.2 \\
\mathrm{R}^{2}=0.967\end{array}$ & $\begin{array}{l}\theta=45.5 \mathrm{mg} / \mathrm{g} \\
\mathrm{b}=0.13 \mathrm{~L} / \mathrm{mg} \\
\mathrm{K}_{\mathrm{L}}=5.9 \mathrm{~L} / \mathrm{g} \\
\mathrm{R}_{\mathrm{L}}=0.13 \\
\mathrm{R}^{2}=0.979\end{array}$ \\
\hline Freundlich & $\ln q_{e}=\ln K_{F}+\frac{1}{n} C_{e}$ & $\begin{array}{l}\mathrm{n}=1.8 \mathrm{~L} / \mathrm{mg} \\
\mathrm{K}_{\mathrm{F}}=8.74 \mathrm{~L} / \mathrm{g} \\
\mathrm{R}^{2}=0.974\end{array}$ & $\begin{array}{l}\mathrm{n}=2.7 \mathrm{~L} / \mathrm{mg} \\
\mathrm{K}_{\mathrm{F}}=8.63 \mathrm{~L} / \mathrm{g} \\
\mathrm{R}^{2}=0.991\end{array}$ \\
\hline Temkin & $q_{t}=B \ln K_{T}+B \ln C_{e}$ & $\begin{array}{l}\mathrm{B}=22.9 \\
\mathrm{~K}_{\mathrm{T}}=0.58 \mathrm{~L} / \mathrm{g} \\
\mathrm{R}^{2}=0.960\end{array}$ & $\begin{array}{l}\mathrm{B}=7.05 \\
\mathrm{~K}_{\mathrm{T}}=3.39 \mathrm{~L} / \mathrm{g} \\
\mathrm{R}^{2}=0.967\end{array}$ \\
\hline
\end{tabular}

Based on $\mathrm{R}^{2}$ values the order of isotherm in both the surfaces are Freundlich > Langmuir > Temkin (i.e.) multilayer lateral adsorption is possible. So the adsorption mechanism is same whereas the maximum adsorption capacity $(\theta=125 \mathrm{mg} / \mathrm{g})$ is greater in the composite bead form than powder form of sawdust $(45.5 \mathrm{mg} / \mathrm{g})$.

The pseudo first order, pseudo second order, intra particle diffusion and simple Elovich kinetic models were tested to investigate the rate of adsorption of $\mathrm{Cr}(\mathrm{VI})$ by SDCCB and ASDP. The linearised form of adsorption kinetics and their constants are given in Table 3.

Table 3. Summary of parameters for various kinetic models

\begin{tabular}{|c|c|c|c|}
\hline Kinetic model & Linear equation & $\begin{array}{c}\text { Constants for } \\
\text { SDCCB }\end{array}$ & Constants for ASDP \\
\hline $\begin{array}{l}\text { Pseudo } \\
\text { first order }\end{array}$ & $\begin{array}{l}\ln \left(q_{e}-q_{t}\right)= \\
\quad \ln q_{e}-K_{1_{a d} t}\end{array}$ & $\begin{array}{l}\mathrm{K}_{1 \mathrm{ad}}=0.034 \mathrm{~min}^{-1} \\
\mathrm{R}^{2}=0.877\end{array}$ & $\begin{array}{l}\mathrm{K}_{1 \mathrm{ad}}=0.019 \mathrm{~min}^{-1} \\
\mathrm{R}^{2}=0.955\end{array}$ \\
\hline $\begin{array}{l}\text { Pseudo } \\
\text { second order }\end{array}$ & $\frac{t}{q_{t}}=\frac{1}{K_{2 a d} \cdot q_{e}^{2}}+\frac{t}{q_{e}}$ & $\begin{array}{l}\mathrm{q}_{\mathrm{e}}=25 \mathrm{mg} / \mathrm{g} \\
\mathrm{K}_{2 \mathrm{ad}}=0.0043 \\
\mathrm{~g} / \mathrm{mg} / \mathrm{min} \\
\mathrm{h}=2.7 \mathrm{mg} / \mathrm{g} / \mathrm{min} \\
\mathrm{R}^{2}=0.994\end{array}$ & $\begin{array}{l}\mathrm{q}_{\mathrm{e}}=23.3 \mathrm{mg} / \mathrm{g} \\
\mathrm{K}_{2 \mathrm{ad}}=0.0084 \\
\mathrm{~g} / \mathrm{mg} / \mathrm{min} \\
\mathrm{h}=4.6 \mathrm{mg} / \mathrm{g} / \mathrm{min} \\
\mathrm{R}^{2}=0.999\end{array}$ \\
\hline $\begin{array}{l}\text { Simple } \\
\text { Elovich }\end{array}$ & $q_{t}=\beta \ln t+\beta \ln (\alpha \beta)$ & $\begin{array}{l}\alpha=1.2 \mathrm{mg} / \mathrm{g} / \mathrm{min} \\
\beta=3.62 \mathrm{~g} / \mathrm{mg} \\
\mathrm{R}^{2}=0.984\end{array}$ & $\begin{array}{l}\alpha=614 \mathrm{mg} / \mathrm{g} / \mathrm{min} \\
\beta=1.85 \mathrm{~g} / \mathrm{mg} \\
\mathrm{R}^{2}=0.978\end{array}$ \\
\hline $\begin{array}{l}\text { Intraparticle } \\
\text { diffusion }\end{array}$ & $q_{t}=K_{i d} t^{1 / 2}+C$ & $\begin{array}{l}\mathrm{K}_{\mathrm{id}}=0.867 \\
\mathrm{mg} / \mathrm{g} \cdot \min ^{0.5} \\
\mathrm{R}^{2}=0.958\end{array}$ & $\begin{array}{l}\mathrm{K}_{\mathrm{id}}=0.550 \\
\mathrm{mg} / \mathrm{g} \cdot \min ^{0.5} \\
\mathrm{R}^{2}=0.963\end{array}$ \\
\hline
\end{tabular}

Therefore based on $\mathrm{R}^{2}$ values, pseudo second order kinetics is the suitable one in both the surfaces. This adsorption occurs through chemisorption. From the data obtained at different temperatures, the thermodynamic parameters for the adsorption process have been evaluated and shown in Table 4. 
Table 4. Thermodynamic parameters

\begin{tabular}{|c|c|c|c|}
\hline Adsorbent & $\Delta \mathrm{G}^{\mathrm{o}}, \mathrm{kJ} / \mathrm{mol}$ & $\Delta \mathrm{H}^{\mathrm{o}}, \mathrm{kJ} / \mathrm{mol}$ & $\Delta \mathrm{S}^{\mathrm{o}}, \mathrm{J} / \mathrm{K} / \mathrm{mol}$ \\
\hline SDCCB & -3.95 & +45.98 & 164.78 \\
\hline ASDP & -1.31 & -55.04 & 185.98 \\
\hline Suggestion $^{8}$ & $\begin{array}{c}\text { Feasible, } \\
\text { spontaneous, non- } \\
\text { specific diffusion of } \\
\text { ions into pores }\end{array}$ & $\begin{array}{l}\text { Endothermic due to } \\
\text { diffusion on the } \\
\text { adsorbents }\end{array}$ & $\begin{array}{l}\text { Driving forces of non- } \\
\text { specific chemisorptions } \\
\text { at the surface }\end{array}$ \\
\hline
\end{tabular}

\section{Adsorption mechanism}

The adsorption of $\mathrm{Cr}(\mathrm{VI})$ on ASDP and SDCCB occurs in a same kind of multistep process. Initially ion-exchange occurs rapidly due to electrostatic force of attraction between solidsolute interfaces. The $\mathrm{Cr}(\mathrm{VI})$ ions then diffuse slowly into the pores due to specific chemisorptions with active sites of adsorbents. This is the rate-controlling step. This is supported by the effect of $\mathrm{pH}$, and activation parameters. Finally equilibrium is reached due to chelation with chromium binding centres such as $\mathrm{O}^{-}, \mathrm{N}^{-}$or $\mathrm{S}^{2-}$ containing the surface functionality of both the adsorbents ${ }^{9}$.

\section{Conclusion}

Results reveal that both the modified forms of saw dust (i.e. ASDP and SDCCB) can be used as effective, economic and eco-friendly adsorbents to the maximum removal of $\mathrm{Cr}(\mathrm{VI})$ ion (>90\% removal at $\mathrm{pH} 2.0$ ) from aqueous solutions. The feasibility of this adsorption on both the modified surfaces is spontaneous, non-specific, endothermic and the multi-layer chemisorption suitably obeys the pseudo second order on the energetic heterogeneous surface.

On comparing the efficiency of these two surfaces, adsorption isotherm, kinetic models and activation parameters indicate that the modified surface of saw dust behaves as a superior adsorbent in its composite bead form rather than raw powder form because of its maximum adsorption capacity $(\theta=125 \mathrm{mg} / \mathrm{g})$ and higher negative $\Delta \mathrm{G}^{\mathrm{o}}$ value.

\section{Acknowledgement}

The authors thank the respective Managements for providing the necessary facilities.

\section{References}

1. $\quad$ Gupta S and Babu B V, Chem Eng J., 2009, 150(2-3), 352-365.

2. $\quad$ Ansari R and Mosayebzadeh Z, J Iran Chem Soc., 2010, 7(2), 339-350.

3. Sud D, Mahajan G and Kaur M P, Bio Resource Technol., 2008, 99(14), 6017-6027.

4. Crini G, Robert C, Martel B and Badot P M, J Hazard Mater., 2008, 153(1-2), 96-106.

5. Karthiheyan T, Rajagopal S and Miranda L R, J Hazard Mater., 2005, B124(1-2), 192-199.

6. Hamadi N K, Chen X D, Farid M M and Lu M G Q, J Chem Eng., 2001, 84(2), 95-105.

7. EI- Ashtoukhy E S I, Amin N K and Abdel Wahab O, Desalination, 2008, 223, 162-173

8. Cestari A R, Vieria E F S and Mota J A, J Hazard Mater., 2008, 160(2-3), 337-343.

9. Shukla A, Zhang Y, Dubey P, Margrave J L and Shukla S, J Hazard Mater., 2002, B95(1-2), 137-152. 